\title{
The Investigation of English Learning Belief of College Students
}

\author{
Zhen Zhou \\ Foreign Languages College, Nanchang Normal University, Nanchang, Jiangxi, 330032 \\ zoye100@sina.com
}

\begin{abstract}
Keywords: English major; Learning belief; Learning aptitude; Learning difficulty; The nature of language learning
\end{abstract}

\begin{abstract}
The research conducts a questionnaire survey and interview on the "beliefs of the language learning" of English major juniors in a normal university of Jiangxi province. And the results indicate that the learning belief of university students is of a medium level, of which motivation expectation ranks first, learning strategy and communicative strategy second; Most students overestimate their learning difficulty, underestimate their learning aptitude, and they have some wrong ideas about the nature of English learning. Thus the result could be of some help to know more about the English learning belief of English majors so as to improve the English teaching efficiency in the normal university.
\end{abstract}

\section{Introduction}

In the language study, learning belief means belief or attitude on the language learning process that learners form through personal understanding or external influence, and it is one of the factors to decide the success of language study. At present, the research into learning belief has become a hot issue in the field of second language acquisition, and many scholars and experts carry out researches into language learning belief from different angles, and obtain a lot of fruits. Horwitz and Cotterall did study on the classification and feature of the learning belief, and he put forward the definition of language learning belief earliest, and he classified language learning belief into five parts, that is, language aptitude, language learning difficulty, language learning nature, learning strategy and social strategy, and motivation-expectation. Many researches indicate that learning belief is closely related to such variables as: cognitive factor, learning strategy, learning style, students' character, self-efficacy, learning anxiety, self-regulated study, cultural background, individual differences, different schools, gender, class, major and so on. Above all, the research in to English majors in the second class normal university on their language learning belief is still quite scarce.

The article did a questionnaire survey on junior English majors in a particular second class normal university on their 'English learning belief", tried to explore the English majors' situation of English learning belief and analyzed the relationship between English learning belief and English academic scores. And the research result will be of great significance to enrich the foreign language learning belief research and of great reference to promote the college English teaching equality.

\section{Research Method}

Research Subjects. The research subjects are English major juniors in a particular second class normal university in Jiangxi Province. There are 105 students from 3 randomly chosen classes of similar academic level. The questionnaires were delivered and retrieved in class in the autumn semester in 2016. The actual retrieval questionnaires are 100 pieces, among which 90 are female, and 10 are male.

Research Instrument. The research subject employs the methods of questionnaire investigation and interview to acquire data and materials. The questionnaire adopts "Beliefs about language learning inventory" (The Chinese version) designed by Hurwitz (1987). The questionnaire administers Likert's five-scale measuring system, which contains 34 items, including five components, that is, language learning aptitude, language learning difficulty, language learning nature, learning and social strategy and motivation-expectation. The author pre-tested the credibility, efficiency and did the item analysis. The reliability of the questionnaire is $\mathbf{0 . 9 1 0 6}$. The English score is students' CET4 score. Moreover, as for 
the interview, five students are chosen randomly from each class. The interview lasts for 8 minutes for each interviewee, whose purpose is to make some reasonable explanation for the answering of the questionnaire.

Data Processing. The 100 effective questionnaire data are input to the computer and processed with SPSS 19.0 software and analyzed using the descriptive statistics and correlation analysis methods.

\section{Research Findings and Analysis}

Learning Belief. Learning belief guides our learning behavior and they are of vital importance to the English study. Students' English learning belief, English scores and all the factors of learning belief are analyzed by descriptive analysis. The result shows that in general, the score of students' learning score is not high, which suggests that students' English learning belief is of a medium level, and the rank of all the factors of learning belief is as follows: motivation-expectation, learning and social strategy, language learning difficulty, language learning nature and learning aptitude. The mean of students' CET 4 score is 478, and the SD is as large as 36, which is a very high figure. This indicates that as for English majors, their English score is not satisfactory at all on the whole. Among all the factors of learning belief, the score of students' motivation-expectation is the highest, which means that students' English learning motivation is strong and clear. And students attach some attention to learning and social strategy, which means that they are willing to communicate with peer classmates, teachers or other people, and they can realize the importance of cultivating comprehension language ability. But the scores of students' belief of language learning difficulty, language learning nature and language aptitude, which demonstrated that students often overestimate the learning difficulty, their understanding of language learning nature is still vague and there exist some errors, and they mostly underestimate their learning aptitude.

Learning Aptitude. The learning aptitude is relatively the stable special ability in the language learning process. The descriptive analysis of every question item of the learning aptitude shows that up tp $82 \%$ of students think that children can learn a foreign language much more easily. The result is not consistent with that of Dai Weidong. Dai points out that children and adults have their respective advantages in learning a foreign language. Children do not learn English more quickly and easily than adults and their advantages are mainly reflected in psychology and physiology. Children's pronunciation may be more idiomatic and accurate, but as to some difficult language content, adults seem to have more edge, which have stronger self-control, more mature minds, and they can adjust their cognitive and meta-cognitive methods consciously in order to achieve better learning effects.

$79 \%$ students think that some people have a special ability to learn a foreign language, and $62 \%$ of students hold a neutral view on "Chinese people are good at learning a foreign language.", and they think that learning a foreign language is the same and equal for people from different countries. Besides, $47 \%$ students think that it is easier for people to learn another language if they have been able to speak one language and they believe the function of language transfer. $70 \%$ of students do not think that "I have the special ability to learn a foreign language", and they think that they are just good at English study, but can not achieve the level of "special ability". Only 19\% of students approve of "Women are better at English than men." And most students deny the gender differences in the language learning. 54\% of students think that "The people who can speak several languages are smart.", and 33\% of students think that "Everyone can learn a foreign language." In conclusion, most students just believe that some people have more gift for learning a foreign language, but they do not think that they have a gift for learning English, which indicates that most students hold a conservative attitude towards their own foreign language learning aptitude.

Learning Difficulty. Everyone is affected by different kinds of obstacles in the learning process in a sense. Through the analysis, the result shows that $87 \%$ of students think that some languages are easier than other languages. The mean of Question 3 is the highest, and the deviation is also the smallest, which means that most students can realize the specialty and uniqueness of different languages. Moreover, $43 \%$ of students think that English ia an easy language. Therefore, most students can realize the characteristics of the English learning, and the major feature of English stands out, which shows that most students have a relatively correct view about the English learning. $45 \%$ of students think that they 
themselves can learn English well and they have some confidence. However, 55\% of students do not think that they can learn English well, which is contradicted with their choice of major. The interview shows that some students choose the English major merely because of better job chance or parents' intention. If we spend one hour learning a foreign language, $41 \%$ of students think that it will take 3 to 5 years to learn a foreign language well. Only $27 \%$ of students think that speaking English is easier than understanding English, and 36\% of students think that speaking and writing English are much easier than listening and speaking.

Language Nature. The research conducts a descriptive statistics of students' belief on language nature and it finds out that $89 \%$ of students believe that it is necessary to know about the culture of English countries in order to learn English, and 74\% of students think that it is best for language learners to go to English-speaking countries to learn English. And most students can realize that the important influence of culture and language environment. Besides, $24 \%$ of students think that the most important thing to learn a foreign language is to learn the vocabulary. $40 \%$ of students keep neutral. And 55\% of students keep a neutral view on the point "The most important thing to learn a foreign language is to learn its grammar", which indicates that students' great concern on English grammar and it is closely related to Chinese test-oriented education. 55\% of students oppose the view "The most important part of learning a foreign language is to learn to translate it into their mother tongue.", and they think that it is important to think in the foreign language.

Learning and Social strategy. The learning strategy monitors and adjusts students' learning process. The investigation result of students' learning and social strategy demonstrates that $94 \%$ of students think that a good English pronunciation is very important. It is well know that a good pronunciation is our face, which influences other English skills. And 76\% of students oppose the view that only if we can pronounce English correctly, can we open our mouth, and they emphasize the fluency of English expression rather than accuracy, and they think that English learning should be a process of repeated practicing. $88 \%$ of students believe that we should guess the new and strange words and they think that the word-guessing strategy is one of the most frequently use learning strategies. And $84 \%$ of students think it is important to do much practice and the English learning demand a lot of practice. $63 \%$ of students like to practice English with English native speakers who they meet. However, 52\% of students feel timid or shy when speaking English with others. 54\% students think that if the English beginners are allowed to make mistakes, they can not speak correctly in the future, and $22 \%$ of students keep a neutral view, and $86 \%$ of students think that it is important to use English recording to practice, after all, the English context in class or after class is far from enough.

Motivation-expectation. Motivation-expectation is the inner force to directly promote students' learning. And the result indicates that $63 \%$ of students approve that Chinese think speaking English is important, which reflects China's current situation, that is, we emphasize practical communication ability more. $26 \%$ of students think that learning English is to know more about English native speakers, and $75 \%$ of students think that is we can learn English well; We have more chance to find a decent job, which suggests that most students' English learning motivation is external instrumental motivation. 94\% of students want to learn well, and $80 \%$ of students want to make friends with English native speakers. Hence, most students' English learning motivation is clear and strong, which is mainly external motivation, and there is a little inner motivation.

\section{The Correlation Analysis of English Learning Belief and English Score}

The correlation analysis is done on English learning belief, its factors and CET4 scores, and the outcome reveals that these variables are not correlated to each other at all. The learning belief has a certain effect on the English score, but not correlated. This result is different from that of Liu Runqing's research, which shows that motivation is highly negatively correlated with students' score and the language learning nature is correlated with language learning nature. As for the different results, the reason may be that the research subjects are different and learners' language learning belief may be just a mediate variable affecting English learning score. 


\section{Conclusion}

The learning belief guides students' learning behavior and right English belief are of great significance to guide students' English learning. The research result indicates that the general level of students' English learning belief is of a medium level. In the learning belief, students' motivation-expectation is strongest and then the learning and social strategy. They are not confident on their English learning, and they have a vague understanding of the nature of English learning. Besides, the learning belief has some influence on the English score but they are not correlated.

The result can offer some reference for the college English teaching. Firstly, the teacher should improve students' cognitive level of English learning belief and they should guide students to develop the function of correct learning belief. The teacher should help correct students' wrong language belief and help them build right learning belief, cultivate students' confidence of English learning, guide students to make positive attribution and boost students' learning self-efficacy. Secondly, the teacher should use flexible teaching methods to guide students to learn English actively, happily and initiatively. Thirdly, the English learning belief is not correlated with English score. The relationship between learning belief and English score is complicated. Thus, some further study should be carried out by experts and scholars.

\section{Acknowledgements}

This work was supported by the school project of Nanchang Normal University, named "The research into college students' English learning belief and learnijng strategy." (15RWYB21).

\section{References}

[1] Bernat, E. Assessing EAP learners' beliefs about language learning in the Australian context [J]. Asian EFL Journal, 2006, 8(2): 202-227.

[2] Cotterall, S. Key variables in language learning: What do learners believe about them? [J]. System, 1999, 27 (4):493-513.

[3] Horwitz, Elaine K. "Surveying student beliefs about language learning." In A. Wenden \& J. Rubin (Eds.), Learner strategies in language learning. United Kingdom: Prentice-Hall, 1987.119-129.

[4] Li Yang. The investigation analysis of language learning belief of non-English majores [J].Overseas English, 2013, (11):119-121.

[5] Song Tiehua. The investigation research of Australian L2 learners [J].. PLA foerien languages study university, 2014,37(5):44-49.

[6] Wu Guangjun. The translation learning belief and its developing feature[J]. oreign language world, 2013,(1):72-78.

[7] Yang, Nae-Dong. The Relationship between EFL Learners' Beliefs and Learning Strategy Use[J]. System, 1999 27(3): 515-535. 